\title{
Desenvolvimento do rudimento seminal em Borreria verticillata (L.) G. Mey. (Rubiaceae - Rubioideae - Spermacoceae)
}

\author{
KAREN L.G. DE TONI ${ }^{1,3}$ e JORGE E.A. MARIATH ${ }^{2}$
}

(recebido: 12 de fevereiro de 2003; aceito: 20 de novembro de 2003)

\begin{abstract}
Ovule development in Borreria verticillata (L.) G. Mey. (Rubiaceae - Rubioideae - Spermacoceae)). The structural characteristics of the ovule formation are an important tool for the systematics of the Rubiaceae family. This paper describes the ovule ontogeny and ginosporogenesis (megasporogenesis) of Borreria verticillata (L.) G. Mey. in order to classify this species based on the evolutive diagrams proposed for the Rubiaceae family. The studied species presents an inferior, bicarpellate, bilocular ovary, with one ovule per loculus. The ovule is anatropous, unitegmic, and tenuinucellate, with axial placentation. The ovule primordia present three distinct layers of cells: dermal, subdermal and central. The integument, nucellar epidermis and ovule primordia originate respectively by divisions in the dermal, subdermal and central layers. The archesporium is constituted by one to five cells, while the nucellar epidermis has two to three cells. One to three ginospore mother cells, originated by divisions in archesporial cells, undergo meiotic divisions developing a linear tetrad. Only the chalazal ginospore remains and becomes functional. The remnant cells from the external integument, the inclusion of the nucellus in the chalaza, the occurrence of few elongated cells in the nucellar epidermis and the increased number of archesporial cells classify the ovule formation of $B$. verticillata in the Mitracarpus type.
\end{abstract}

Key words - Borreria, integument, nucellus, ovule, Rubiaceae

RESUMO - (Desenvolvimento do rudimento seminal em Borreria verticillata (L.) G. Mey. (Rubiaceae - Rubioideae Spermacoceae)). O uso de caracteres embriológicos tem-se mostrado promissor para relacionar subfamílias, tribos, gêneros e espécies de Rubiaceae. A partir da ginosporogênese (megasporogênese) e formação do rudimento seminal (óvulo) de Borreria verticillata (L.) G. Mey. este trabalho visa enquadrar a espécie nas propostas evolutivas já existentes para Rubiaceae, além de disponibilizar informações para a taxonomia do gênero. A espécie possui ovário ínfero, bilocular e bicarpelar, com um rudimento seminal por lóculo, que, em seu desenvolvimento completo, é anátropo, unitegumentado e tenuinucelado, disposto em placentação axial. O primórdio seminal possui três camadas: dérmica, subdérmica e central. O início da formação do rudimento se dá por divisões não preferenciais da camada central. Em seguida, células derivadas da camada dérmica originam o tegumento e a epiderme nucelar. $\mathrm{O}$ arquespório é composto por uma a cinco células arquesporiais e a epiderme nucelar por duas a três células. Do conjunto de células arquesporiais, de uma a três se desenvolvem em células-mãe de ginósporos (células-mãe de megásporos), cuja meiose origina uma tétrade linear, sendo funcional o ginósporo (megásporo) calazal. Comparando os resultados obtidos com a literatura especializada enquadra-se $B$. verticillata no tipo Mitracarpus, devido à presença de remanescentes do tegumento externo, inclusão do nucelo na calaza, ao número reduzido de células alongadas na epiderme nucelar e ao incremento das células arquesporiais.

Palavras-chave - Borreria, nucelo, Rubiaceae, rudimento seminal, tegumento

\section{Introdução}

O gênero Borreria (Rubiaceae - Rubioideae Spermacoceae) possui cerca de 100 espécies (Cabral 1991), distribuídas em regiões tropicais e subtropicais da América, África, Ásia e Austrália, apresentando maior diversidade no planalto brasileiro (Steyermark 1972).

\footnotetext{
1. Instituto de Pesquisas do Jardim Botânico do Rio de Janeiro. Rua Pacheco Leão 915, Jardim Botânico, 22460-030 Rio de Janeiro, RJ, Brasil.

2. Universidade Federal do Rio Grande do Sul. Pesquisador CNPq e-mail: jorge.mariath@ufrgs.br

3. Autor para correspondência: karen@jbrj.gov.br
}

Sob o ponto de vista embriológico, esse gênero foi pouco estudado, existindo apenas trabalhos relativos a Borreria hispida Spruce ex K. Schum. (Farooq 1952) e B. stricta (L. f.) G. Mey. (Vijaya \& Lakshmanan 1979), além de descrições palinológicas feitas por Médus \& Sanakho (1974). Galati (1991) concedeu maior atenção à tribo Spermacoceae, descrevendo a ginosporogênese e ginogametogênese de 17 espécies da tribo, dentre elas oito do gênero Borreria.

$\mathrm{Na}$ família Rubiaceae, os pioneiros em estudos embriológicos foram: Schleiden (1837), o qual forneceu elementos relacionados à disposição anátropa e a ausência de tegumento nos rudimentos seminais das espécies da família; Lloyd (1899), que indicou a presença de um tegumento em alguns gêneros, contrariando 
Schleiden (1837), que descreveu a condição ategumentada para Houstonia; e, Fagerlind (1937) que sugeriu a análise de tendências evolutivas de características do rudimento seminal na família.

A partir das idéias apresentadas por Fagerlind (1937), outros trabalhos foram realizados, como Andronova (1977), Galati (1991) e Mariath \& Cocucci (1997), acrescentando informações ou modificando a proposta inicial.

Com o objetivo de fornecer dados que auxiliem na complementação do quadro evolutivo da família, este trabalho visa descrever a formação e desenvolvimento do rudimento seminal (óvulo) ao longo da ginosporogênese (megasporogênese) de $B$. verticillata (L.) G. Mey., buscando enquadrar seu modelo de diferenciação entre os demais já propostos.

\section{Material e métodos}

Botões florais e flores em sucessivos estágios de desenvolvimento foram coletados nos Campi da Universidade Federal do Rio Grande do Sul (UFRGS). Após a dissecação do material, a fixação foi realizada em glutaraldeído 1\% e formaldeído 4\% (McDowell \& Trump 1976), em tampão fosfato de sódio $0.1 \mathrm{M}, \mathrm{pH} 7,2$. A desidratação foi realizada através da série alcoólica etílica e inclusão em hidroxietilmetacrilato (Gerrits \& Smid 1983). O material foi seccionado longitudinalmente em micrótomo de rotação Zeiss Mikron, com 2-4 $\mu \mathrm{m}$ de espessura. Depois de aderidos às lâminas, os cortes foram corados com Azul de Toluidina $\mathrm{O}$ 0,05\% (O’Brien \& McCully 1981). As observações e a obtenção de fotomicrografias foram realizadas em microscópio óptico Leitz Dialux 20 EB.

\section{Resultados}

Borreria verticillata (L.) G. Mey. apresenta ovário ínfero, bicarpelar e bilocular, com um rudimento seminal por lóculo (figura 1). Ao completar seu desenvolvimento o rudimento é anátropo, unitegumentado e tenuinucelado; porém, antes de assumir essa conformação anátropa definitiva, apresenta posição hemítropa, resultado de sua expansão inicial a partir da placenta. Além do único tegumento, observa-se a presença de resquício do tegumento externo (figura 2).

O início da formação do ovário (figura 3) dá-se após a diferenciação dos verticilos do cálice, corola e estames. Após a ocorrência de divisões periclinais nas margens da parte residual do meristema floral determinado, há formação das paredes do ovário, que se estendem como projeções sobre a placenta, ocasionando seu fechamento. A parede do ovário, que cresce em direção à corola, origina o estilete. Nesse estágio, a placenta é comum aos dois lóculos (figura 4), porém distinta em duas porções, devido ao achatamento ocasionado pelo fechamento e crescimento do ovário.

Em $B$. verticillata, a placentação é axial-basal, gerando então rudimentos seminais na base do lóculo (figuras 1,2).

Após o fechamento dos carpelos, há transição de uma estrutura placentária (com características de túnica e corpo) para uma estrutura de dois primórdios rudimentares que, através de divisões celulares, estabelecem três camadas, sendo possível distinguir uma dérmica, uma subdérmica e uma central (figura 5). Nessa etapa do desenvolvimento os primórdios seminais apresentam, nas camadas dérmica (camada I) e subdérmica (camada II), divisões celulares exclusivamente anticlinais e, na camada central, as divisões celulares são anticlinais e periclinais.

Devido às divisões da camada central, o rudimento seminal assume a curvatura hemítropa (figura 6); sendo nessa fase que se estabelece a epiderme nucelar e o tegumento. $\mathrm{O}$ início do desenvolvimento do tegumento se dá a partir de divisões periclinais das células da camada dérmica, contíguas à epiderme nucelar, que possui aspecto plano durante todo o desenvolvimento do rudimento seminal, com um leve alongamento de suas células no sentido anticlinal (figura 7). Na camada subdérmica, de uma a cinco células, posicionadas junto à epiderme nucelar, diferenciam-se em células arquesporiais, apresentando citoplasma denso e núcleo proeminente. Nesse estágio de desenvolvimento, o nucelo apresenta epiderme nucelar, com duas a três células, e arquespório inserido na região calazal (figura 7).

Seguindo o desenvolvimento, de uma a três células arquesporiais maturam diretamente como célula-mãe de ginósporos (célula-mãe de megásporos) (figura 7). Dessas apenas uma, após aumentar em até duas vezes seu volume inicial e assumir uma forma alongada, com o pólo micropilar levemente mais largo que o calazal, origina uma tétrade linear ao final da meiose (figura 8).

A tétrade linear apresenta impregnação de calose nas paredes periclinais e anticlinais dos três ginósporos (megásporos) micropilares. Embora em menor grau, a calose também está presente nas paredes anticlinais e na periclinal externa do ginósporo calazal, que é o funcional (figura 8). O ginósporo calazal leva à formação do ginófito (gametófito feminino), enquanto os ginósporos micropilares sofrem degeneração.

Concomitante à maturação das células arquesporiais, há formação do tegumento externo vestigial, a partir de divisões periclinais das células da 
camada subdérmica (figura 9); destaca-se que, em seção longitudinal, as indicações da figura 9 evidenciam um verdadeiro "colar" ou "anel" que circunscreve o perímetro do rudimento seminal na altura da base calazal, antes da curvatura do funículo.

Após sucessivas divisões celulares, ocorridas na camada dérmica, o tegumento interno alcança o topo do nucelo e suas margens projetam-se além desse ponto, formando a micrópila (figura 9); uma vista geral pode ser evidenciada na figura 2 , anteriormente citada. Nesse estágio de desenvolvimento, o funículo apresenta uma curvatura de $180^{\circ}$, em relação à micrópila, caracterizando o rudimento anátropo.

O ginósporo calazal se expande consideravelmente, tornando-se uma célula alongada com núcleo bastante conspícuo e de posição central (figura 10). Há o desenvolvimento de pequenos vacúolos nos dois pólos da célula, caracterizando a célula-mãe do ginófito (célula-mãe do saco embrionário). Tais vacúolos coalescem e, no final do estágio uninucleado, a célulamãe de ginófito apresenta ampla vacuolação bipolar, iniciando o processo de ginogametogênese (megagametogênese) cujo resultado final é a formação de um ginófito do tipo Polygonum, de origem monospórica (figura 11).

\section{Discussão}

De acordo com Robbrecht (1988), a condição ínfera e bicarpelar dos ovários de Rubiaceae é uma das características mais confiáveis para definir e reconhecer as espécies da família. Porém, há exceções, como observado em estágios precoces do desenvolvimento floral de Otiophora lebruniana (Bamps) E. Robbrecht \& C. Puff (Robbrecht \& Puff 1981) e em Calanda (Puff \& Robbrecht 1989), em que o ovário apresenta redução com relação ao número de carpelos; entretanto, em Theligonum, as flores apresentam ovário unicarpelar sem traços de um segundo carpelo (Rutishauser et al. 1998).

A placentação axial é comum a todas as Rubiaceae, porém sua inserção no eixo do carpelo é variável (Robbrecht 1988). Quando os rudimentos seminais são formados na porção mediana do septo carpelar, a placentação é do tipo axial. Porém, quando formados a partir da porção apical do septo, a placentação axial é do tipo apical, originando rudimentos seminais pêndulos. Mas, se os rudimentos se desenvolvem na porção basal do septo, essa placentação é do tipo basal, formando rudimentos seminais eretos, como em $B$. verticillata.
Em Rubiaceae, o número de rudimentos seminais varia de um a numerosos, sendo esse caráter tradicionalmente usado para distinção de subfamílias (Bremekamp 1966). Muitas tribos possuem, estritamente, um rudimento por lóculo, como: Vanguerieae, Guettardeae, Knoxieae, Psychotrieae, Rubieae e Spermacoceae (incluindo a espécie em questão).

Segundo Galati (1991), as espécies do gênero Borreria apresentam rudimentos seminais, durante todo o período de desenvolvimento, em posição anátropa. Essa constatação diverge do observado no presente trabalho, pois além da conformação anátropa, observouse a hemítropa, em fases precoces do desenvolvimento. Por outro lado, Vijaya \& Lakshmanan (1979) constataram que o rudimento de $B$. stricta é anfítropo em sua maturidade. A variabilidade de caracteres embriológicos entre espécies do mesmo gênero não é comum, pois de acordo com Herr (1984), as características embriológicas são extremamente conservativas, mesmo entre gêneros de uma mesma tribo.

A não uniformidade dos resultados, encontrados por Vijaya \& Lakshmanan (1979) e Galati (1991), pode estar demonstrando problemas taxonômicos relacionados ao gênero Borreria, cujas inflorescências e flores são os principais caracteres para agrupamento de espécies (Chamisso \& Schlechtendal 1828). Esses problemas taxonômicos já haviam sido discutidos por Cabral (1991), que, após uma detalhada análise taxonômica no gênero, envolvendo grãos de pólen, cromossomos, folhas, inflorescências, flores, frutos e sementes, efetuou uma nova classificação com relação à delimitação do gênero e dos subgêneros de Borreria.

Enquanto assume a posição hemítropa, tem início, no rudimento seminal, a diferenciação do tegumento e da epiderme nucelar. A origem dérmica do tegumento, como ocorre em $B$. verticillata, é comum entre as angiospermas, com exceções na família Euphorbiaceae (Bouman 1984), onde ambos os tegumentos são de origem subdérmica. Seguindo o padrão de $B$. verticillata têm-se registros em Richardia brasiliensis Gomes, de acordo com as representações de Galati (1991); em Jacaranda mimosifolia D. Don (Galati \& Strittmatter 1999), em Gentiana cruciata L. e G. asclepiadea L. (Bouman \& Schier 1979) e na família Rafflesiaceae (Bouman \& Meijer 1994).

Na espécie analisada, ocorrem divisões periclinais na camada subdérmica do rudimento seminal, não envolvendo as células arquesporiais; essas divisões indicam a presença de vestígio de tegumento externo. 

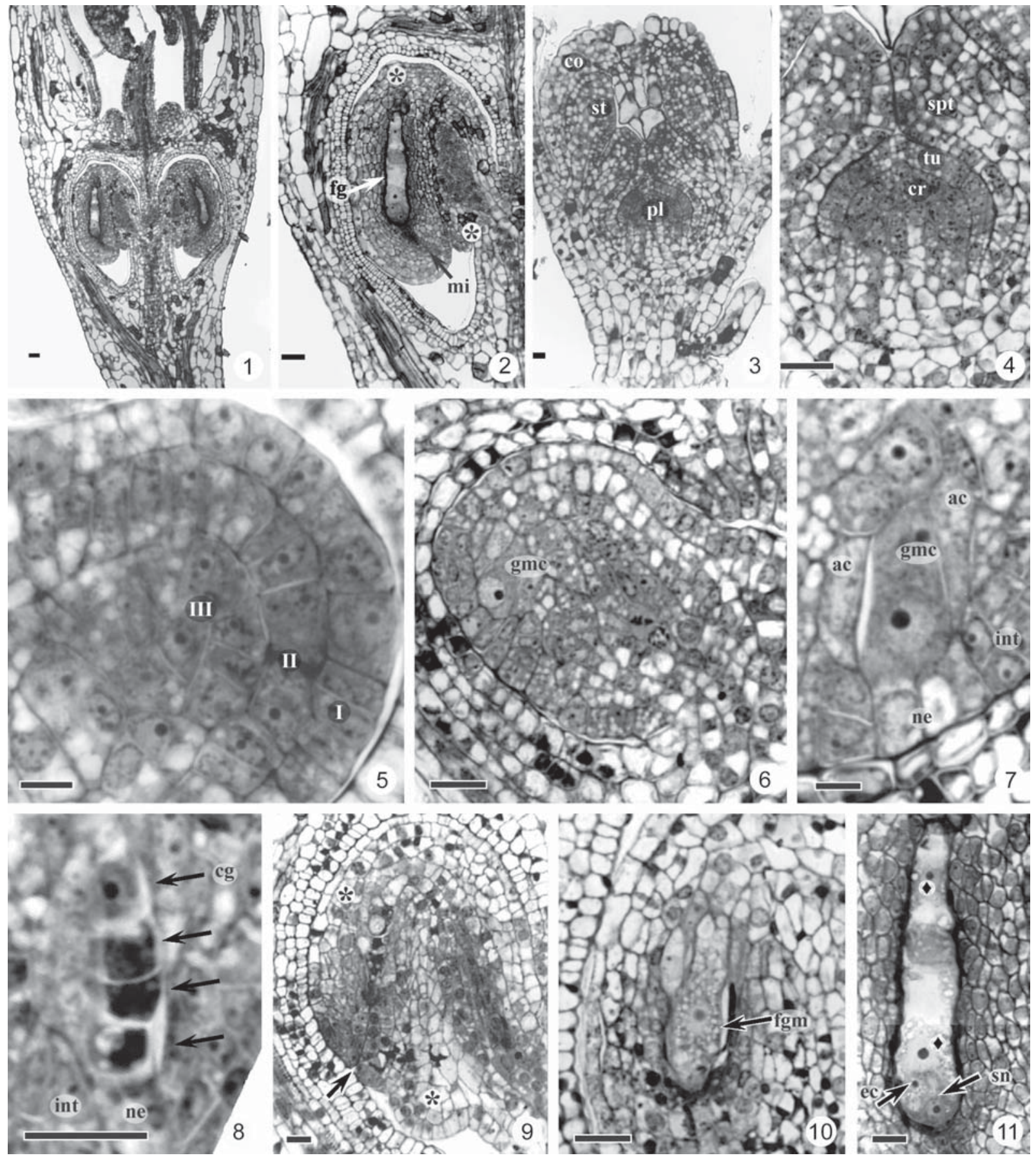

Figuras 1-11. Desenvolvimento do rudimento seminal e ginosporogênese (megasporogênese) de Borreria verticillata. 1. Secção longitudinal do botão floral evidenciando ovário ínfero, bicarpelar, bilocular com um rudimento seminal por lóculo. 2. Pormenor do rudimento seminal anátropo, unitegumentado, com resquício do tegumento externo $(*)$, ginófito completo (fg) e micrópila (mi). 3. Seç̧ão longitudinal do carpelo em formação, evidenciando corola (co), estames (st) e placenta (pl). 4. Detalhe do septo (spt) e da placenta - túnica (tu) e corpo (cr), no carpelo em secção longitudinal. 5. Secção longitudinal do primórdio seminal trizonado (camadas I, II e III). 6. Rudimento seminal hemítropo, com célula-mãe de ginósporos (gmc), em secção longitudinal. 7. Detalhe das células arquesporiais (ac), célula-mãe de ginósporos (gmc), epiderme nucelar (ne) e início da formação do tegumento (int), a partir de secção longitudinal do rudimento seminal. 8. Detalhe da tétrade linear (ginósporos indicados por setas), destacando o ginósporo calazal funcional (cg), tegumento (int) e epiderme nucelar (ne). 9. Secção longitudinal do rudimento em posição anátropa, com resquício do tegumento externo $(*)$ e micrópila indicada por seta. 10. Célula-mãe de ginófito (fgm). 11. Detalhe do ginófito, evidenciando sinérgide (sn), oosfera (ec), núcleos da célula média ( $\bullet$ ); as antípodas e uma sinérgide não estão visíveis nesse plano de corte. Barras $=10 \mu \mathrm{m}$. 
$\mathrm{Na}$ literatura, o vestígio de tegumento externo é citado erroneamente como estrofíolo, porém, de acordo com Lloyd (1899), Fagerlind (1937), Font-Quer (1985) e Robbrecht et al. (1991), o estrofíolo é uma estrutura de origem funicular.

Periasamy \& Parameswaran (1965) consideram o estrofíolo como remanescente filogenético do arilo, que perdeu sua função e individualidade. A presença do estrofíolo é registrada em Richardsonia e Diodia (Lloyd 1899), Borreria hispida (Raghavan \& Srinivasan 1941), Guettarda speciosa L. (Raghavan \& Srinivasan 1941) e Richardia brasiliensis (Inamuddin \& Farooq 1984). Nessas espécies é difícil esclarecermos se a estrutura em questão é realmente o estrofíolo ou vestígio do tegumento externo, para tanto, estudos ontogenéticos devem ser realizados.

$\mathrm{Na}$ família Rubiaceae o número de células arquesporiais varia, sendo constituído por uma ou por várias células. Se composto por somente uma célula arquesporial, esta atuará diretamente como célula-mãe de ginósporos, como ocorre em: Borreria hispida (Raghavan \& Srinivasan 1941), Dentella repens (L.) J.R. Forst. (Raghavan \& Rangaswamy 1941), Oldenlandia alata Roxb. (Raghavan \& Rangaswamy 1941), Tarenna asiatica (L.) Kuntze ex K. Schum. (Periasamy \& Parameswaran 1965), Oldenlandia nudicaulis Roth (Farooq \& Inamuddin 1969), B. stricta (Vijaya \& Lakshmanan 1979), Richardia brasiliensis (Inamuddin \& Farooq 1984) e algumas espécies de Diodia, Mitracarpus, Spermacoce e Staelia (Galati 1991).

Quando composto por um conjunto de células, quaisquer das células arquesporiais têm a potencialidade de se transformar em célula-mãe de ginósporo, como ocorre em Oldenlandia corymbosa L. (Farooq 1958), Octodon setosum Hiern (Andronova 1973) e Relbunium hypocarpium (L.) Hemsl. (Mariath \& Cocucci 1997) e em algumas espécies da tribo Rubieae (Lloyd 1899, Fagerlind 1937, Venkateswarlu \&
Rajeswara Rao 1958, Andronova 1988). Em B. verticillata, até três células do arquespório atuam diretamente como células-mãe de ginósporos, o mesmo ocorrendo nas espécies da tribo Spermacoceae analisadas por Galati (1991).

Borreria verticillata possui rudimento seminal tenuinucelado, ou seja, a célula-mãe de ginósporos está diretamente em contato com a epiderme nucelar, que nessa espécie se constitui em uma camada de três a cinco células. Assim como os tegumentos, o nucelo também apresenta valor taxonômico. A maioria das eudicotiledôneas é tenuinucelada e unitegumentada, somando um total de 105 famílias (Rangan \& Rangaswamy 1999).

Com a maturação da célula-mãe de ginósporos, o processo meiótico consiste em duas divisões transversais e sucessivas, que originam uma tétrade linear de ginósporos, como na espécie aqui estudada. Além de tétrades lineares, freqüentes em Rubiaceae, podem ser encontradas tétrades em tetraedro (Fadogia cienkowskii Schweinf. - Andronova 1972); em forma de " $T$ " (Oldenlandia corymbosa - Farooq 1958), ou em " $T$ " invertido (Farooq \& Inamuddin 1969).

A deposição de calose em $B$. verticillata foi observada em todas as paredes dos ginósporos, exceto na parede periclinal interna do ginósporo funcional. Registros similares não foram encontrados para outras espécies da família. A formação de calose durante a ginosporogênese é um fenômeno de ampla ocorrência nas angiospermas e está envolvida, entre outros aspectos, com o isolamento temporário dos ginósporos, que acarreta seu desenvolvimento independente (Bouman 1984).

O ginósporo calazal é desde o início favorecido, não só pelo seu posicionamento, nutricionalmente mais vantajoso pela proximidade com a calaza, como pela distribuição da calose na tétrade como um todo. A celularização e a simultânea deposição de calose sobre as paredes da tétrade obstruem de imediato a livre

Figures 1-11. Ovule development and ginosporogenesis (megasporogenesis) of Borreria verticillata. 1. Inferior, bicarpellate, bilocular ovary, with one ovule per loculus (longitudinal section). 2. Anatropous and unitegmic ovule, remnant cells from the external integument $(*)$, female gametophyte (fg) and micropyle (mi). 3. Carpel development, corolla (co), stamens (st) and placenta (pl). 4. Ovary septum (spt) and placenta - tunica (tu) and corpus (cr). 5. Trizonate ovular primordium (layers I, II and III). 6. Hemitropous ovule, with ginospore mother cell (gmc). 7. Archesporial cells (ac), ginospore mother cells (gmc), nucellar epidermis (ne), and the beginning of inner integument (int) establishment. 8. Linear tetrad, arrows indicate the ginospores (megaspores), showing functional chalazal ginospore (cg), the integument (int) and the nucellar epidermis (ne). 9. Anatropous ovule with remnant cells from the external integument $\left(^{*}\right)$ and micropyle indicated by arrow. 10. Female gametophyte mother cell (fgm). 11. Female gametophyte with one synergid (sn), egg cell (ec) and nuclei from the central cell ( $\bullet$ ); the antipodals and the other synergid are not visible in this section. Bars $=10 \mu \mathrm{m}$. 
difusão de nutrientes entre os ginósporos, o que favorece sua degeneração. Além disso, tem-se sugerido que a calose tem papel fundamental durante a apoptose dos três ginósporos micropilares (Angenent \& Colombo 1996).

Existem propostas a respeito da possível evolução dos rudimentos seminais na família Rubiaceae (Fagerlind 1937, Andronova 1977, Galati 1991, Mariath \& Cocucci 1997). Essas indicam variações morfológicas evidenciando linhas evolutivas distintas relacionadas à formação do tegumento e do nucelo. $B$. verticillata apresenta as seguintes tendências: redução do tegumento externo, inclusão do nucelo na calaza, redução e alongamento da epiderme nucelar, e incremento do arquespório.

As alterações morfológicas que indicam transição dos rudimentos seminais bitegumentados para os unitegumentados podem ser explicadas pelo desaparecimento (eliminação ou retardamento) ou fusão de um dos dois tegumentos (Bouman 1984). Existem famílias que apresentam rudimentos com estruturas intermediárias, ou seja, tegumento interno bem desenvolvido, ao contrário do tegumento externo, que se apresenta reduzido, porém evidente. Esses rudimentos não podem ser classificados como bitegumentados ou unitegumentados, sendo, então, classificados como rudimentos de tegumento bífido (Bouman 1984), como ocorre em algumas Ranunculaceae, Rosaceae, Anacardiaceae, Balsaminaceae, Coriaceae, Lecythidaceae, Meliaceae, Ochnaceae, entre outras (Mauritzon 1939).

Em Rubiaceae os rudimentos seminais são exclusivamente unitegumentados (Robbrecht 1988), porém foram verificadas, em alguns gêneros, alterações morfológicas nessa estrutura, ou seja, a família possui rudimentos seminais com tegumento externo reduzido. A redução do tegumento externo, observada, nesse estudo, em $B$. verticillata, também já foi registrada nos gêneros Phyllis, Psychotria (Fagerlind 1937), Ophiorrhiza, Coffea, Ixora, Mussaenda, Macrosphyra, Tricalysia, Scyphiphora, Knoxia, Cephalanthus, Hoffmannia, Chiococca, Rondeletia, Stephygyne (Andronova 1977) e Paederia (Svoma 1991). Essas análises sugerem que os primórdios seminais primitivos foram bitegumentados; portanto, os ancestrais das Rubiaceae pertenceriam a táxons que possuíssem esta condição. A característica unitegumentada, a partir da bitegumentada, deve ter sido alcançada várias vezes ao longo da evolução das angiospermas (Bouman 1984).
As demais tendências evolutivas relatadas em B. verticillata, de inclusão do nucelo na calaza, redução no número de células da epiderme nucelar e o alongamento das mesmas, são resultantes do encadeamento de eventos pertinentes ao nucelo.

A inclusão do nucelo na calaza torna-se perceptível devido à alteração na morfologia do ápice nucelar que, de um aspecto de domo (onde a epiderme nucelar envolve as células-mãe dos ginósporos e as demais células nucelares), passa a se diferenciar no seio da calaza com uma epiderme de aspecto pavimentoso e plano (Fagerlind 1937) que, apesar de apresentar uma redução no número de células, conserva suas mesmas características citológicas.

Por fim inicia-se o alongamento radial da epiderme nucelar. As manifestações desse fenômeno são encontradas em Mitracarpus (Galati 1991), em Relbunium (Mariath \& Cocucci 1997) e alcança sua máxima expressão em Rubia olivierii A.Rich. (Mariath \& Cocucci 1997), que, neste último caso, além de apresentar as células da epiderme nucelar alongadas, também apresenta redução do número de células arquesporiais.

Outro aspecto a ser destacado é a redução do arquespório que ocorreu, provavelmente, de forma independente durante a evolução da família (Fagerlind 1937, Andronova 1977, Mariath \& Cocucci 1997). Porém, analisando-se a série evolutiva da subfamília Rubioideae, proposta por esses autores, vê-se que, a partir do tipo Phyllis, ocorre antes um incremento do tecido arquesporial, seguido de sua redução nas diferentes séries. Esse aumento no número de células arquesporiais é evidente se compararmos o tipo Phyllis com o tipo Mitracarpus, pois há um aumento de duas para até cinco células, respectivamente; como observado em espécies da tribo Spermacoceae, na qual se enquadra $B$. verticillata.

Quando se confronta o rudimento seminal de B. verticillata com o das espécies já estudadas por Fagerlind (1937), Andronova (1977), Galati (1991) e Mariath \& Cocucci (1997), percebe-se que a espécie em questão se aproxima mais do tipo Mitracarpus, instituído por Galati (1991) e reconhecido por Mariath \& Cocucci (1997). Para uma visualização esquemática destas inter-relações evolutivas e maiores detalhes, sugere-se consulta a Mariath \& Cocucci (1997).

Agradecimentos - À Capes e ao CNPq pelas bolsas concedidas, de Mestrado à primeira autora e de Pesquisa ao segundo autor, respectivamente, bem como à Fapergs pelo auxílio. Aos colegas do Laboratório de Anatomia Vegetal da Universidade Federal do Rio Grande do Sul. 


\section{Referências bibliográficas}

ANDRONOVA, N.N. 1972. A contribution to the embryology of Fadogia cienkowskii Schweinf. Botanische Zeitung 57:826-831.

ANDRONOVA, N.N. 1973. To the embryology of Octodon setosum Hiern. (Rubiaceae). Botanische Zeitung 58:1371-1377.

ANDRONOVA, N.N. 1977. On the structure of the ovule of Rubiaceae. Botanische Zeitung 62:1461-1469.

ANDRONOVA, N.N. 1988. Comparative characteristics of the ovule structure of some Rubieae species (Rubiaceae). Botanische Zeitung 73:674-682.

ANGENENT, G.C. \& COLOMBO, L. 1996. Molecular control of ovule development. Trends in Plant Science 1:228-232.

BOUMAN, F. 1984. The ovule. In Embryology of Angiosperms (B.M. Johri, ed.). Springer-Verlag, Berlin, p.123-157.

BOUMAN, F. \& MEIJER, W. 1994. Comparative structure of ovules and seeds in Rafflesiaceae. Plant Systematics and Evolution 193:187-212.

BOUMAN, F. \& SCHIER, S. 1979. Ovule ontogeny and seed coat development in Gentiana, with a discussion on the evolutionary origin of the single integument. Acta Botanica Neerlandica 28:467-478.

BREMEKAMP, C.E.B. 1966. Remarks on the position, the delimitation and the subdivision of the Rubiaceae. Acta Botanica Neerlandica 15:1-33.

CABRAL, E.L. 1991. Rehabilitación del gênero Galianthe (Rubiaceae). Boletin de la Sociedad Argentina de Botanica 27:217-231.

CHAMISSO, L.A. \& SCHLECHTENDAL, D.F. 1828. Rubiaceae, De plantis in expeditione speculatoria Romanzoffiana observatis rationem dicunt. Linnaea 3:309-341.

FAGERLIND, F. 1937. Embryologische, zytologische und bestäubungsexperimentelle Studien in der Familie Rubiaceae nebst Bemerkungen über einige Polyploiditätsprobleme. Acta Horti Bergiani 2:196-470.

FAROOQ, M. 1952. The embryology of Borreria hispida (Spermacoce hispida): a reinvestigation. Current Science 21:252-253.

FAROOQ, M. 1958. The embryology of Oldenlandia corymbosa. Journal of Indian Botany Society 37:358-364.

FAROOQ, M. \& INAMUDDIN, M. 1969. The embryology of Oldenlandia nudicaulis Roth. Journal of Indian Botany Society 48:166-173.

FONT-QUER, P. 1985. Diccionario de Botánica. Editorial Larbor, Barcelona.

GALATI, G.G. 1991. Estúdios embriológicos em la tribu Spermacoceae (Rubiaceae). Parte I: Anatomia Floral. Megasporogénesis. Megagametogénesis. Boletin de la Sociedad Argentina de Botanica 27:7-20.

GALATI, B.G. \& STRITTMATTER, L.I. 1999. Ovule ontogeny and megasporogenesis in Jacaranda mimosifolia D. Don (Bignoniaceae). Phytomorphology 49:67-74.
GERRITS, P.O. \& SMID, L. 1983. A new, less toxic polymerization system for the embedding of soft tissues in glycol methacrylate and subsequent preparing of serial sections. Journal of Microscopy 132:81-85.

HERR, J.M. 1984. Embryology and taxonomy. In Embryology of Angiosperms (B.M. Johri, ed.). Springer-Verlag, Berlin, p.647-696.

INAMUDDIN, M. \& FAROOQ, M. 1984. The embryology of Richardia brasiliensis Gomes (syn. Richardsonia pilosa H.B. \& K.) (Rubiaceae) - a reinvestigation. Pakistan Journal of Botany 16:139-144.

LLOYD, F.E. 1899. The comparative embryology of the Rubiaceae. Memoirs of the Torrey Botanical Club 8:1-111.

MARIATH, J.E.A. \& COCUCCI, A.E. 1997. The ovules of Relbunium hypocarpium in the context of the Rubiaceae. Kurtziana 25:141-150.

MAURITZON, J. 1939. Contribution to the embryology of the orders Rosales and Myrtales. Acta Lund 2, 35:1-121.

MCDOWELL, E. \& TRUMP, B. 1976. Histological fixatives for diagnostic light and electron microscopy. Archives of Pathology Laboratory Medicine 100:405-414.

MÉDUS, J. \& SANAKHO, A. 1974. Description palynologique de quelques espèces des genres Borreria G.F.W. Mey (Rubiaceae) et Hygrophila R. Br. (Acanthaceae). Bulletin de l'Institut Fondamental d'Afrique Noire. Serie A, Science Naturalles 36:379-391.

O'BRIEN, T.P. \& MCCULLY, M.E. 1981. The study of plants structure: principles and selected methods. Termarcarphi Pty, Melbourne.

PERIASAMY, K. \& PARAMESWARAN, N. 1965. A contribution to the floral morphology and embryology of Tarenna asiatica. Beiträge zur Biologie der Pflanzen 41:123-138.

PUFF, C. \& ROBBRECHT, E. 1989. A survey of the Knoxieae (Rubiaceae-Antirheoideae). Botanische Jahrbücher für Systematik Pflanzengeschichte und Pflanzengeographie 110:511-558.

RAGHAVAN, T.S. \& RANGASWAMY, K. 1941. Studies in the Rubiaceae. I. Development of female gametophyte and embryo formation in Dentella repens Forst. and Oldenlandia alata Koch. and some cyto-taxonomical considerations. Journal of Indian Botanical Society 20:341-356.

RANGAN, T.S. \& RANGASWAMY, N.S. 1999. Nucellus - a unique embryologic system. Phytomorphology 49:223-335.

RAGHAVAN, T.S. \& SRINIVASAN, A.R. 1941. Studies in Rubiaceae. II. Spermacoce hispida L., Guettarda speciosa L. and some cytomorphological considerations. Proceedings of the Indian Academy of Science 14:412-426.

ROBBRECHT, E. 1988. Tropical Woody Rubiaceae. Characteristic features and progressions. Contributions to a new subfamilial classification. Opera Botanica Belgica 1:1-271. 
ROBBRECHT, E. \& PUFF, C. 1981. Mericocalyx Bamps, synonymous with Otiophora Zucc. (Rubiaceae). Bulletin du Jardin Botanique National de Belgique 51:143-151.

ROBBRECHT,E., PUFF, C. \& IGERSHEIM, A. 1991. The genera Mitchella and Damnacanthus - evidence for their close alliance; comments on the campylotropy in the Rubiaceae and the circumscription of the Morindeae. Blumea 35:307-345.

RUTISHAUSER, R., RONSE DECRAENE, L.P., SMETS, E. \& MENDOZA-HEUER, I. 1998. Theligonum cynocrambe: developmental morphology of a peculiar rubiaceous herb. Plant Systematics and Evolution 210:1-24.
SCHLEIDEN, M.J. 1837. Einige Blicke auf die Entwicklungsgeschichte des vegetabilischen Organismus bei den Phanerogamen. Archiv für Natur Geschichte 1:289-414.

STEYERMARK, J.A. 1972. Borreria G.F. Meyer. The Botany of the Guayana Highland-part IX. Memoirs of the New York Botanical Garden 23:805-831.

SVOMA, E. 1991. The embryology of Paederia L. (Rubiaceae - Paederieae). Opera Botanica Belgica 3:115-122.

VENKATESWARLU, J. \& RAJESWARA RAO, G. 1958. A contribution to the life history of Rubia cordifolia. Journal of Indian Botany Society 37:442-454.

VIJAYA, V. \& LAKSHMANAN, K.K. 1979. Embryological studies in the Rubiaceae. II. Borreria stricta K. Schum. Journal of Madras University, Section B 42:26-34. 